\title{
Profound decrease of liver maximum function capacity test of isoflurane sedated patients: A report of three cases
}

\author{
Elke Schwier $^{1}$ () | Carmen Kirchner ${ }^{2}$ | Claas Eickmeyer ${ }^{1}$ | Günther Winde ${ }^{2}$ | \\ Dietrich Henzler $^{1}$ | Thomas Köhler ${ }^{1} \odot$ \\ ${ }^{1}$ Department of Anesthesiology, Surgical Intensive Care, Emergency and Pain Medicine, Ruhr University Bochum, Klinikum Herford, Herford, \\ Germany \\ ${ }^{2}$ Department of General and Visceral Surgery, Thoracic Surgery and Proctology, Ruhr University Bochum, Klinikum Herford, Herford, Germany
}

\section{Correspondence}

Thomas Köhler, Universitätsklinik für Anästhesiologie, Operative

Intensivmedizin, Rettungsmedizin und Schmerztherapie der Ruhr-Universität Bochum, Klinikum Herford,

Schwarzenmoorstr. 70, D-32049

Herford, Germany.

Email: thomas.koehler@klinikum-

herford.de

\section{Funding information}

There are no financial arrangements related to the report or assistance with manuscript preparation

\begin{abstract}
LiMAx 13C-methacetin breath test results should be interpreted with caution in patients sedated with isoflurane.
\end{abstract}

\section{K E Y W O R D S}

AnaConDa, CYP1A2, isoflurane, LiMAx

\section{1 | BACKGROUND}

Unexpectedly low LiMAx values were measured in isoflurane sedated patients. Possible causes are a reduced cytochrome P450 (CYP) 1A2 enzyme activity or interaction of isoflurane with CYP1A2 or with the breath test itself. We propose that LiMAx test results should be interpreted with caution in isoflurane sedated patients.

Treatment of critically ill patients often requires mechanical ventilation accompanied by sedation. The most common first-line sedative drug is intravenous propofol. ${ }^{1}$ Despite pharmacological advantages over other intravenous sedatives, propofol has substantial side effects. These are impairment of the cell function, overload with triglycerides and triggering or amplification of delirium. An increasingly used alternative to propofol is the inhalative sedation with isoflurane that is available for intensive care settings since the approval of the Anaesthetic Conserving Device (AnaConDa, $100 \mathrm{ml}$, Sedana Medical) in 2004. Due to its ease of use, safe application of volatile anesthetics, and compatibility with all common types of intensive care respirators, the system has quickly found its way into many intensive care units. $^{2}$ We use isoflurane in cases of chronic obstructive pulmonary disease and pneumonia with recurrent bronchoobstruction, intracranial pathology, assuming an ICP measurement is established, or when the required sedation period exceeds the recommended limit of propofol application (7 days).

Intensive care patients are continuously monitored with regard to various organ systems and functional parameters. The development of acute liver failure (ALF) or 
acute-on-chronic liver failure (ACLF) is associated with increased mortality in sepsis. ${ }^{3}$ In general, differentiated assessment of liver function is essential for early diagnosis and treatment. If treatment for ACLF is started during the therapeutic ,golden window the chances for liver recovery are increased. ${ }^{4}$

Only few parameters of liver function are available in septic patients, such as serum bilirubin concentration and INR. ${ }^{5}$ The model of end-stage liver disease (MELD) score $^{6}$ had been developed for non-ICU patients and is unprecise for dialyzed patients. Other prognostic scoring systems such as the Chronic Liver Failure Consortium ACLF score (CLIF-C ACLFs), CLIF Consortium Acute Decompensation (CLIF-C ADs) score, and the ChildPugh score ${ }^{7-9}$ assess among others the impairment of consciousness and are thus not suitable for sedated patients.

A prognostic test with higher sensitivity and specificity and a good correlation with Child-Pugh- and MELD Score in non-sedated patients is the LiMAx test (Humedics $\mathrm{GmbH}$ ). ${ }^{10,11}$ Measurements are independent of neurologic function, which allows application of the test in sedated patients in the intensive care setting. The LiMAx test delivers a quantitative measurement of maximal liver function capacity within $60 \mathrm{~min}$ and has been evaluated in various clinical situations including mechanical ventilation. ${ }^{11,12}$ Briefly, the patient is injected $2 \mathrm{mg} / \mathrm{kg}$ body weight of ${ }^{13} \mathrm{C}$-methacetin intravenously, which is exclusively metabolized to paracetamol in subtherapeutic dose and ${ }^{13} \mathrm{CO}_{2}$ by the hepatic, microsomally localized, hemoprotein enzyme 1A2 (CYP1A2) from the cytochrome $\mathrm{P} 450$ group. ${ }^{13} \mathrm{CO}_{2}$ is a naturally occurring, stable non-radioactive carbon isotope. The exhaled amount of ${ }^{13} \mathrm{CO}_{2}$ is proportional to the total liver function capacity. ${ }^{13}$ The measurement of ${ }^{13} \mathrm{CO}_{2}$ can also be performed via the expiration valve in ventilated patients. A value of $315 \mu \mathrm{g} / \mathrm{kg} / \mathrm{h}$ or above is physiological. ${ }^{12,14,15}$ Below this level, an impairment of liver function should be considered. Any value below $140 \mu \mathrm{g} / \mathrm{kg} / \mathrm{h}$ strongly indicates significant hepatic injury ${ }^{16}$ or an advanced liver cirrhosis. ${ }^{17}$ A value of less than $100 \mu \mathrm{g} / \mathrm{kg} / \mathrm{h}$ in combination with respiratory dysfunction has been associated with increased mortality and may be of prognostic relevance with regard to patient survival. ${ }^{18} \mathrm{~A}$ value of $29-98 \mu \mathrm{g} / \mathrm{kg} / \mathrm{h}$ was observed for patients suffering from terminal liver cirrhosis. ${ }^{17}$

We present a series of three patients from a university hospital surgical intensive care unit for whom extremely low LiMAx test results were observed while receiving inhaled sedation with isoflurane, a finding that had not been reported before. The aim of our investigation was to discuss hypotheses helping to explain these data and a putative causal connection.

\section{CASE PRESENTATION}

Patient A: A 21-year-old, before healthy female patient suffered a severe polytrauma in a motorcycle accident with an injury severity score (ISS) of 75 . The main injuries were severe craniocerebral trauma, severe blunt abdominal trauma with liver rupture and a decollement in the area of the left thigh extending to gluteal. Primary surgical treatment included laparotomy and liver suturing. On the first post-traumatic day LiMAx-value was $305 \mu \mathrm{g} / \mathrm{kg} / \mathrm{h}$, while static liver parameters were massively increased. Hemicraniectomy was performed due to rapidly increasing brain edema. Persistently high intracranial pressure (ICP) values prompted to change the sedation regimen to an inhalative concept with isoflurane under continuous ICP control. While laboratory liver parameters quickly normalized, LiMAx test results were 2 and $3 \mu \mathrm{g} / \mathrm{kg} / \mathrm{h}$ after 25 and $123 \mathrm{~h}$. After the cessation of isoflurane, the LiMAx returned spontaneously to $180 \mu \mathrm{g} / \mathrm{kg} / \mathrm{h}$.

Patient B: A 65-year-old man who had undergone rectum resection for advanced rectal carcinoma developed anastomosis insufficiency with abdominal sepsis. The antimicrobial chemotherapy included the liver-toxic antibiotic linezolid. LiMAx was used to monitor a possible deterioration of liver function at an early stage. The first test result was $151 \mu \mathrm{g} / \mathrm{kg} / \mathrm{h}$. Since the respirator therapy had to be continued for longer than 7 days, sedation was switched to isoflurane. In the further course of treatment, LiMAx decreased to 2 and $10 \mu \mathrm{g} / \mathrm{kg} / \mathrm{h}$. After isoflurane was discontinued LiMAx increased to $254 \mu \mathrm{g} / \mathrm{kg} / \mathrm{h}$ while transaminases also increased.

Patient C: A 49-year-old man had received thoracotomy for a suspicious pulmonary node. After an atypical resection of the right lower lobe, he was transferred to the intensive care unit. In the course of the first postoperative day, an endobronchial hemorrhage occurred with acute deterioration of gas exchange. The bleeding from the middle lobe segment 4 was stopped by epinephrine instillation and tamponades in repeated bronchoscopies. A re-thoracotomy could be avoided. Due to recurrent bronchospastic episodes, isoflurane sedation was established early on. LiMAx test was performed sequentially to assess liver function in perceived sepsis. After an initial reading of $376 \mu \mathrm{g} / \mathrm{kg} / \mathrm{h}$ with propofol, LiMAx values of 33 and $77 \mu \mathrm{g} / \mathrm{kg} / \mathrm{h}$, respectively, were measured under isoflurane sedation. Clinical and laboratory assessment did not correlate with this decrease. After discontinuation of isoflurane LiMAx increased back up to $496 \mu \mathrm{g} /$ $\mathrm{kg} / \mathrm{h}$, other parameters also indicated normal liver function. The patient's demographics and clinical data are listed in detail in Tables 1 and 2, for LiMAx test results in correlation with standard liver parameter and isoflurane see Figure 1. The LiMAx tests were performed according 
TABLE 1 Patients' demographics

\begin{tabular}{|llll|}
\hline & Patient A & Patient B & Patient C \\
\hline Gender & Female & Male & Male \\
\hline Age (years) & 21 & 65 & 49 \\
\hline BMI & 21.7 & 30.9 & 29.8 \\
\hline Major medical history & Polytrauma & Rectum-cancer; post-operative & Lung cancer, right upper lobe resection \\
& & complications & No \\
\hline History of liver disease & No & No & No \\
\hline CRRT treatment & Yes & Yes & Yes \\
\hline Smoker & No & No & Sepsis \\
\hline Reason for suspected liver damage & Trauma & Sepsis, Linezolid & Pulmonary \\
\hline Source of a potential infection & Pulmonary & Abdominal & Yes \\
\hline 28 day survival & Yes & Yes & Pons \\
\hline
\end{tabular}

Abbreviations: BMI, Body Mass Index; CRRT, continuous renal replacement therapy.

to the manufacturer's specifications (Humedics Inc) and the clinical standard. To avoid a possible influence of the metabolism of the hydrophilic ${ }^{13} \mathrm{C}$-methacetin by the continuous renal replacement therapy (CRRT), the latter was paused directly before the start and during each measurement. CRRT was re-started immediately after the end of the measurement.

\section{3 | DISCUSSION AND CONCLUSIONS}

Measurement of liver function capacity in patients at high risk for liver failure is a standard procedure in our institution as a diagnostic tool that can routinely be performed at the bedside when a compromise of liver function is suspected. Since LiMAx can be assessed independently from consciousness it may also be applied for sedated patients. In the three presented cases during isoflurane sedation, the measured values were unexpectedly low in the range of $1-71 \mu \mathrm{g} / \mathrm{kg} / \mathrm{h}$ (Figure 2). We consider several mechanisms for this observation: Interaction of isoflurane with the test procedure itself, interference of isoflurane with CYP1A2 or temporary decrease in liver enzyme activity without liver cell damage ("liver hibernation").

None of the patients had a history of liver disease (e.g. alcoholic liver disease, hepatitis, non-alcoholic fatty liver or cirrhosis) that could have explained reduced liver enzyme activity. Under certain conditions (e.g. shock of different etiology) the liver enzyme activity may be temporarily reduced. The "standard liver parameters" are quantified from the blood and indicate liver damage, however, without reflecting the CYP1A2 enzyme activity. Extremely low LiMAx values were measured in the three patients equally after the start of isoflurane that spontaneously returned to previous values after discontinuation of the inhaled sedative. Meanwhile, neither clinical nor laboratory findings suggested almost complete liver failure, which would be expected from such low LiMAx values. ${ }^{17}$ Polytrauma-caused high liver-associated enzyme (LAE) values of patient A declined continuously over time while LAEs were elevated clinical significantly only at the last measurement in patients B and C (Table 2), matching the clinical pictures in all three cases. Here, isoflurane seems to suspend the known correlation ${ }^{10}$ of LiMAx and LAEs. To rule out toxic effects, all administered drugs were scanned for a known interaction with CYP1A2 in the Flockhart Table ${ }^{19}$ and for a high likelihood of hepatotoxicity in LiverTox. ${ }^{20}$ With the exception of patient B, who received linezolid, none of the patients were treated with a listed drug during the relevant time (Figure 3). The hepatotoxic effect of the oxazolidinone antibiotic linezolid is well known. It is commonly associated with lactic acidosis and leads to an increase in transaminases. Lactic acidosis was not detected and an increase in transaminases was only observed at the time of the last LiMAx measurement, so that a serious impairment of liver function by linezolid at the time of CYP1A2 activity determination is not plausible. Therefore, true liver failure (pre-existing or toxic) as the cause for the significant decrease in LiMAx values seems quite unlikely.

The supply of ${ }^{13} \mathrm{C}$ contained in food or infusions and oxygen have a major influence on the ${ }^{13} \mathrm{CO}_{2} \cdot{ }^{12} \mathrm{CO}_{2}$ ratio measurement. ${ }^{21,22}$ Genetic polymorphisms of CYP1A2 and smoking are supposed only to have a slight influence on the test results. ${ }^{22}$ During the investigated period, food, infusions, and oxygen supply were almost unchanged suggesting no influence on test results.

The LiMAx instruction manual does not mention a possible influence of isoflurane on test results.

Only few studies have investigated a possible interaction of isotope measurement with isoflurane. After 


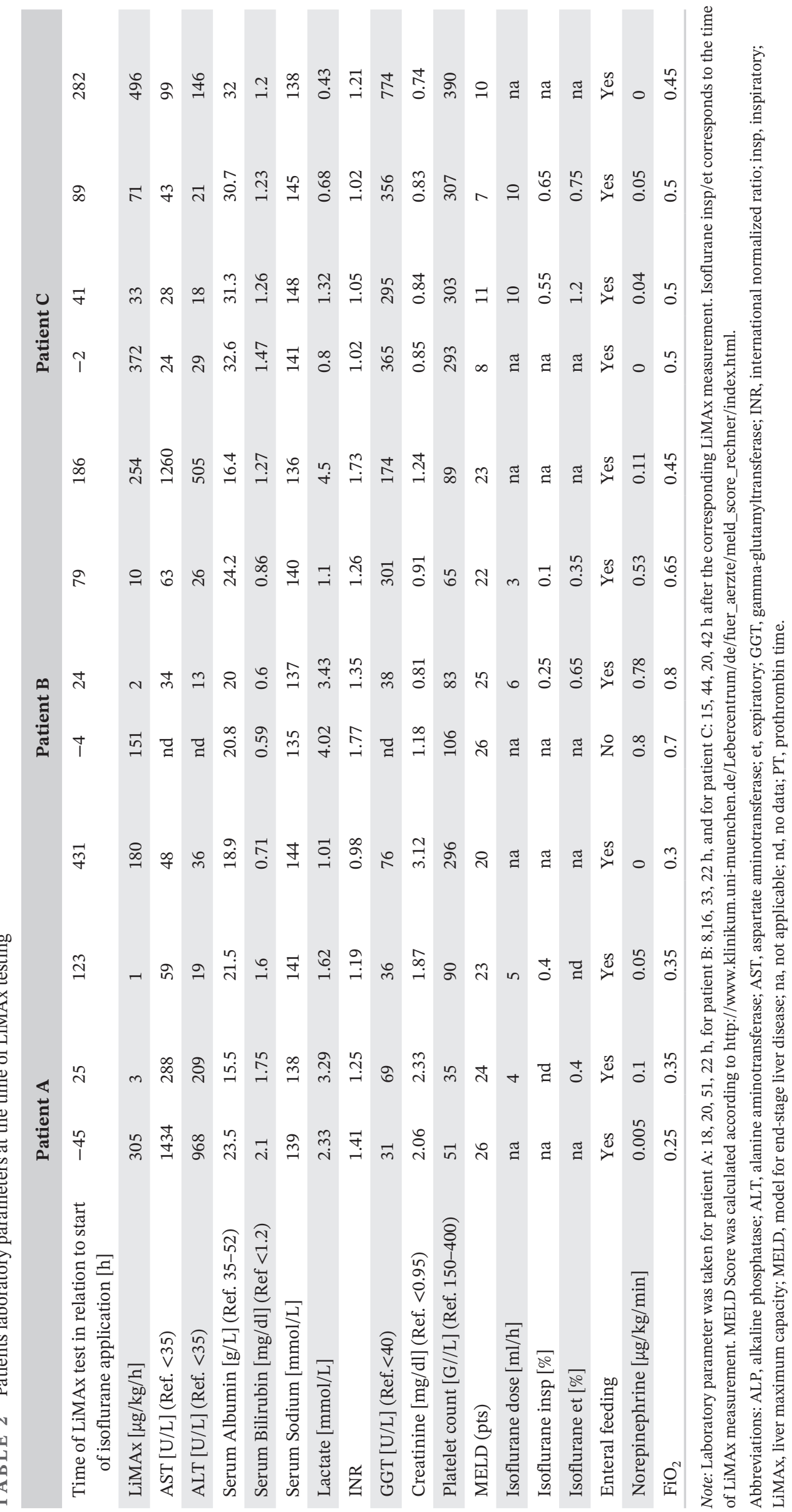



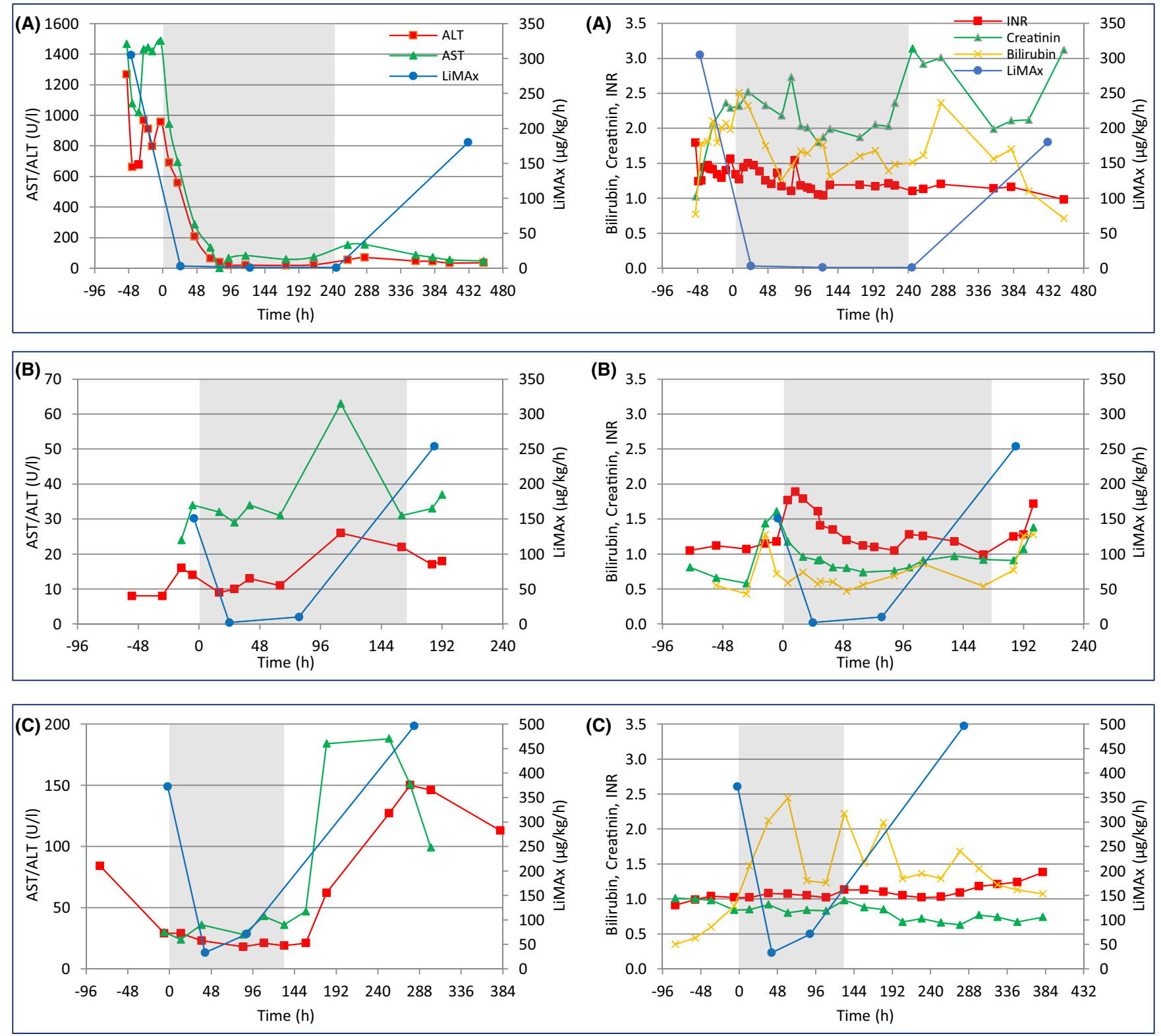

F I G U RE 1 Enzymatic liver function measurement with LiMAx in correlation with standard liver parameter and isoflurane (gray shading). Upper panel: patient A; middle panel: patient B; lower panel: patient C. Abbreviations: ALT: Alanine aminotransferase; AST, Aspartate aminotransferase; INR, International normalized ratio; LiMAx, Liver maximum capacity

measurement of several pig breath samples that contained isoflurane, the quality control drifted further and more quickly from its known value. The authors hypothesized that isoflurane was adsorbed by the gas chromatography column in isotope ratio mass spectrometry (IRMS). ${ }^{23}$ In contrast, LiMAx technology uses laser-based spectrometry and was validated in five patients with total intravenous anesthesia to avoid interference by volatile anesthetics. ${ }^{24}$ Ensle et al. ${ }^{25}$ measured intestinal glucose absorption with a ${ }^{13} \mathrm{C}$ glucose breathing test. Two isoflurane sedated patients were excluded from the analysis because of suspected isoflurane interaction with the ${ }^{13} \mathrm{C}$ measured values, although no excluded values were reported. One could expect decreased LiMAx values if isoflurane prevents the ${ }^{13} \mathrm{C}$-methacetin pre-hepatic transport from the blood stream to the liver. This, however, is unlikely since lipophilic isoflurane accumulates in the fatty tissue while only low concentrations are available in the blood. We conclude that there is no evidence of a relevant interaction between methacetin or ${ }^{13} \mathrm{CO}_{2}$ and isoflurane.

Physiologically, isoflurane is almost inert in endogenous metabolism. It is oxidatively metabolized to a small extent $(\sim 0.2 \%)$ in the liver via CYP2E1 ${ }^{19,26}$ while an interaction of isoflurane and CYP1A2 activity has not yet been described. ${ }^{26,27}$ Even so, negative effects of isoflurane on the liver are well known. The liver damage is caused by 


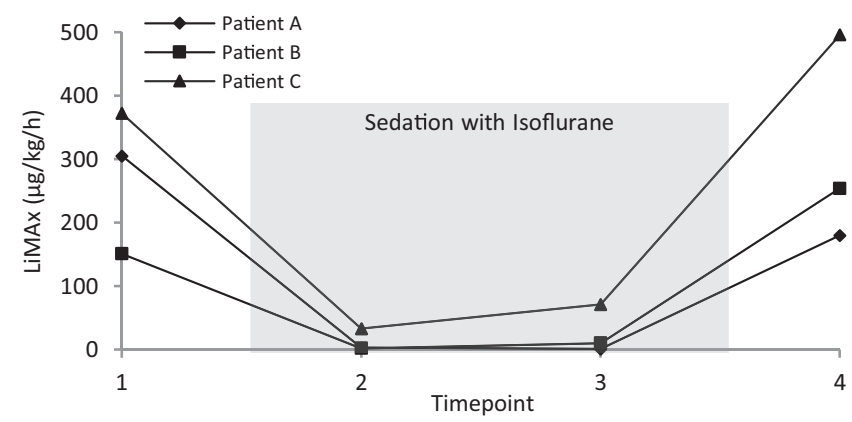

F I G U RE 2 LiMAx test results. Time points; 1 and 4 before/ after isoflurane sedation; 2 and 3 with isoflurane sedation. Abbreviation: LiMAx, Liver maximum capacity
Finally, it remains unclear whether the apparent influence of isoflurane on the LiMAx test is substance-specific or whether other inhaled anesthetics cause similar effects.

To our knowledge, this is the first description of a profound decrease of LiMAx values during simultaneous isoflurane sedation, the reason for which remains unclear. Possible mechanisms are test-specific interactions, an isoflurane-induced reduction in CYP1A2 activity or a temporary shut-down of enzymatic liver function without cell damage, suggesting a hibernating liver in the early phase of severe inflammatory disease. A more frequent measurement of Cyp1A2 activity would be desirable, to describe the development of en-
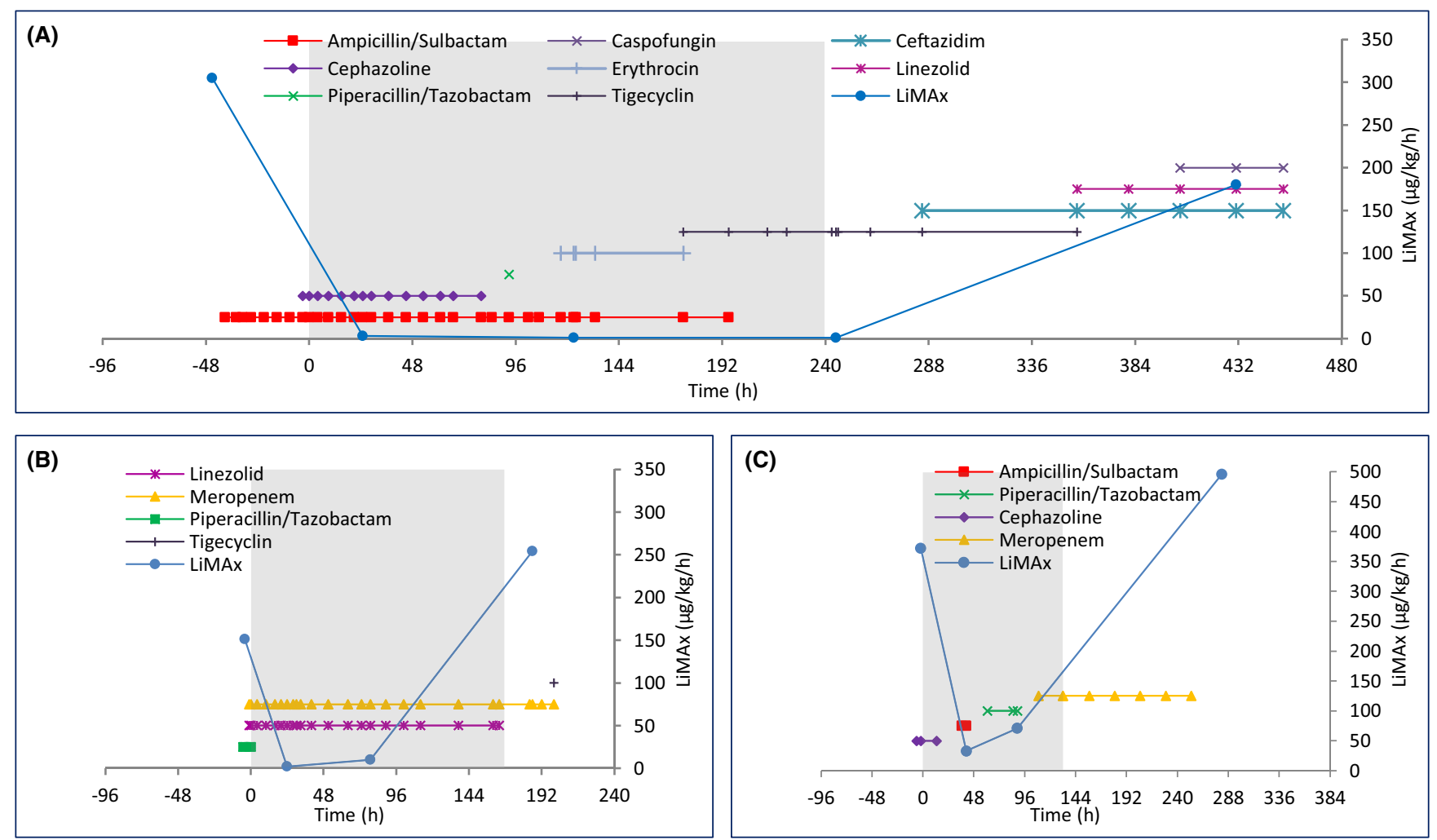

F I G U RE 3 LiMAx test results, isoflurane (gray shading), and antibiotics over time for the three described patients. (A): patient A; (B): patient B; (C): patient C. Abbreviation: LiMAx, Liver maximum capacity

trifluoroacetylation of liver proteins and a subsequent inflammatory reaction and rapid increase of transaminases termed hepatitis. This effect has been particularly well studied for halothane, but is also known for isoflurane. ${ }^{26}$ If in fact, isoflurane does compromise CYP1A2 activity genetic polymorphism could explain the differences in enzyme depression, which was less profound in patient C $(-91 \%)$ as compared to the other patients $(-98 \%$ and $-99 \%$, respectively). ${ }^{28}$ zyme activity more precisely. Due to the increasing use of both LiMAx and inhaled sedation in the ICU, we consider it important to further investigate this possible interaction in order to prevent erroneous measurements and possible wrong clinical decisions. We propose that, until the breath test on enzymatic liver function has been validated in the critical care setting, LiMAx test results should be interpreted with caution in patients sedated with isoflurane. 


\section{ACKNOWLEDGEMENTS}

The authors have confirmed during submission that patient consent has been signed and collected in accordance with the journal's patient consent policy.

A preprint publication is available under https:// www.researchgate.net/publication/348895799_Profo und_Decrease_of_Liver_Maximum_Function_Capac ity_Test_of_Isoflurane_Sedated_Patients_A_Report_of_ Three_Cases Open access funding enabled and organized by ProjektDEAL.

\section{CONFLICT OF INTEREST}

None declared.

\section{AUTHOR CONTRIBUTIONS}

ES performed literature research and wrote the manuscript. CK analyzed and interpreted LiMAx data and reviewed the manuscript. CE performed functional liver testing with LiMAx on intensive care unit, treated the patients, and reviewed the manuscript. DH participated in analyzing and interpreting the data and revised the manuscript. GW helped to interpret the data and to review the manuscript. TK treated the patients on intensive care unit and analyzed and interpreted data and was a major contributor in writing the manuscript. All authors gave final approval of the version to be published and agreed to be accountable for all aspects of the work in ensuring that questions related to the accuracy or integrity of any part of the work are appropriately investigated and resolved.

\section{ETHICAL APPROVAL}

The ethics committee of the medical faculty of the Ruhr University Bochum had approved the anonymous collection and publication of data.

\section{DATA AVAILABILITY STATEMENT}

The datasets used and/or analyzed during the current study are available from the corresponding author on reasonable request.

\section{ORCID}

Elke Schwier (1) https://orcid.org/0000-0002-9279-2986

Thomas Köhler (1) https://orcid.org/0000-0003-0399-8382

\section{REFERENCES}

1. Baron R, Binder A, Biniek R, et al. Evidence and consensus based guideline for the management of delirium, analgesia, and sedation in intensive care medicine. Revision 2015 (DASGuideline 2015) - short version. Ger Med Sci. 2015;13:Doc19.

2. Farrell R, Oomen G, Carey P. A technical review of the history, development and performance of the anaesthetic conserving device "AnaConDa" for delivering volatile anaesthetic in intensive and post-operative critical care. J Clin Monit Comput. 2018;32:595-604.

3. Arroyo V, Moreau R, Jalan R. Acute-on-chronic liver failure. $N$ Engl J Med. 2020;382:2137-2145.

4. Sarin SK, Choudhury A. Acute-on-chronic liver failure. Curr Gastroenterol Rep. 2016;18:61.

5. Woźnica EA, Inglot M, Woźnica RK, Łysenko L. Liver dysfunction in sepsis. Adv Clin Exp Med. 2018;27:547-551.

6. Kamath PS, Kim WR, Group ALDS. The model for end-stage liver disease (MELD). Hepatology. 2007;45:797-805.

7. Jalan R, Saliba F, Pavesi M, et al. Development and validation of a prognostic score to predict mortality in patients with acuteon-chronic liver failure. J Hepatol. 2014;61:1038-1047.

8. Jalan R, Pavesi M, Saliba F, et al. The CLIF consortium acute decompensation score (CLIF-C ADs) for prognosis of hospitalised cirrhotic patients without acute-on-chronic liver failure. $J$ Hepatol. 2015;62:831-840.

9. Pugh RN, Murray-Lyon IM, Dawson JL, Pietroni MC, Williams R. Transection of the oesophagus for bleeding oesophageal varices. Br J Surg. 1973;60:646-649.

10. Malinowski M, Jara M, Lüttgert K, et al. Enzymatic liver function capacity correlates with disease severity of patients with liver cirrhosis: a study with the LiMAx test. Dig Dis Sci. 2014;59:2983-2991.

11. Buechter M, Gerken G, Hoyer DP, et al. Liver maximum capacity (LiMAx) test as a helpful prognostic tool in acute liver failure with sepsis: a case report. BMC Anesthesiol. 2018;18:71.

12. Kaffarnik MF, Ahmadi N, Lock JF, et al. Correlation between plasma endothelin-1 levels and severity of septic liver failure quantified by maximal liver function capacity (LiMAx test). A prospective study. PLoS One. 2017;12:e0178237.

13. Stockmann M, Lock JF, Malinowski M, Niehues SM, Seehofer D, Neuhaus P. The LiMAx test: a new liver function test for predicting postoperative outcome in liver surgery. $H P B$. 2010;12:139-146.

14. Stockmann M, Vondran FWR, Fahrner R, et al. Randomized clinical trial comparing liver resection with and without perioperative assessment of liver function. BJS Open. 2018;2:301-309.

15. Wicha SG, Frey OR, Roehr AC, et al. Linezolid in liver failure: exploring the value of the maximal liver function capacity (LiMAx) test in a pharmacokinetic pilot study. Int J Antimicrob Agents. 2017;50:557-563.

16. Humedics. LiMAx Quantifying functional liver capacity. https://www.humedics.eu/en/why-limax.html. Accessed October 12, 2020.

17. Stockmann M, Lock JF, Malinowski M, Scharfenberg A, Morawietz L, Neuhaus P. Accurate diagnosis and grading of cirrhosis using the new LiMAx Test. J Hepatol. 2012;56:S422.

18. Kaffarnik MF, Lock JF, Vetter H, et al. Early diagnosis of sepsis-related hepatic dysfunction and its prognostic impact on survival: a prospective study with the LiMAx test. Crit Care. 2013;17:R259.

19. Flockhart DA. Drug interactions: cytochrome P450 drug interaction table. 2007. Indiana University School of Medicine, Indianapolis. https://drug-interactions.medicine.iu.edu. Accessed October 12, 2020.

20. National Institute of Diabetes and Digestive and Kidney Diseases LiverTox, clinical and research information on 
drug-induced liver injury. Bethesda. 2012. https://www.ncbi. nlm.nih.gov/books/NBK547852/. Accessed October 12, 2020.

21. Riecke B, Neuhaus P, Stockmann M. Major influence of oxygen supply on $13 \mathrm{CO} 2: 12 \mathrm{CO} 2$ ratio measurement by nondispersive isotope-selective infrared spectroscopy. Helicobacter. 2005;10(6):620-622.

22. Stockmann M. Predictive value of a new method for the determination of the liver function in liver surgery (LiMAx test). 2009. https://refubium.fu-berlin.de/handle/fub188/11367. Accessed October 12, 2020.

23. Matthews T, Trochsler M, Barry S, Kuchel T, Zacharakis B, Maddern G. Possible isoflurane effect observed in isotope ratio mass spectrometry from a large animal model. J Exp Appl Anim Sci. 2016;2:71.

24. Stockmann M, Lock JF, Riecke B, et al. Prediction of postoperative outcome after hepatectomy with a new bedside test for maximal liver function capacity. Ann Surg. 2009;250:119-125.

25. Ensle F. Messung der Glukoseabsorption mittels 13CAtemgastest als Marker für die intestinale Funktionalität bei Intensivpatienten. Open Access Repositorium der Universität Ulm und Technischen Hochschule Ulm. Dissertation. 2020. http://dx.doi.org/10.18725/OPARU-25246. Accessed October 13, 2020.
26. Njoku D, Laster MJ, Gong DH, Eger EI, Reed GF, Martin JL. Biotransformation of halothane, enflurane, isoflurane, and desflurane to trifluoroacetylated liver proteins: association between protein acylation and hepatic injury. Anesth Analg. 1997;84:173-178.

27. Nee J, Schroeder T, Vornholt F, et al. Dynamic determination of functional liver capacity with the LiMAx test in post-cardiac arrest patients undergoing targeted temperature management-a prospective trial. Acta Anaesthesiol Scand. 2020;64:501-507.

28. Genetic polymorphisms of cytochrome P450 (CYP) $1 \mathrm{~A} 2$. Evidence-Based Medicine Consult. 2015. https://www.ebmco nsult.com/articles/pharmacogenetics-cyp1a2-genetic-polym orphisms-table. Accessed October 1, 2020.

How to cite this article: Schwier E, Kirchner C, Eickmeyer C, Winde G, Henzler D, Köhler T. Profound decrease of liver maximum function capacity test of isoflurane sedated patients: A report of three cases. Clin Case Rep. 2021;9:e04862. https://doi.org/10.1002/ccr3.4862 